Editorial

\title{
Dental implants: to do or not to do!
}

\section{Editorial}

Today's dentistry is immensely influenced by the concept of functionality \& aesthetics to the extent that the dental surgeon is overlooking the age old golden rule of conservative dentistry. In most practices today, Dental Implants are increasingly becoming a rule rather than a replacement option. Overtreatment in the field of dental Implantology is almost like the law of the land \& is unfortunately pushing behind other conventional prosthodontic procedures such as the Post \& Core etc. The world of dental Implantology faces a couple of issues that are seeding themselves \& burrowing through norms of ethical dental practice. Holding the bull by its horns, the first of the ailment lies at the very take off, the point of education. Self styled courses \& institutes have mushroomed through the past few years which claim to make the 'cyclist' into a 'fighter pilot'. Misleading institutes over-armour the general dental practitioner into the pseudo-belief of being a qualified implantologist who sets out to war without the weaponry of comprehensive knowledge. The second evil is the 'Death of consciousness' wherein the implantologist has adopted the religion of crossing the bridge before it comes. In my opinion, dental implants should be the last resort. To the newer age implantologist, an implant procedure seems to be the law of the land. Extraction followed by an implant is becoming the next mandate for the patient who does not even know whether he needs one or not. The age long phrase has probably been tweaked to 'Overpromise \& Under deliver'. Unnecessary placement of implants in teeth that can be saved by endodontic \& prosthodontic means is shifting that thin red line of ethical practice towards the adverse extreme.

I am sure, even Dr Branemark would be ashamed up there in heaven to see the sharp curve that Implantology is being subjected to in the light of advancements in dentistry. In the wake of professionalism, I appeal to all my fellow dental surgeons to be a part of the movement

\author{
Volume 2 Issue 2 - 2015
}

\section{Saurabh Lall}

Department of Periodontology and Implant Dentistry, Clove Dental chain of clinics, India

Correspondence: Saurabh Lall, Department of Periodontology and Implant Dentistry, Clove Dental chain of clinics, I-A Masjid Moth, Neeti Bagh,South Extension, New Delhi, India, Email saurabhlall.delhi@gmail.com

Received: April 20, 2015 | Published: April 28, 2015

to reform the system \& fold that accusing finger into a fist that pledges to restore the dignity of the profession of dentistry by pledging to enhance ethical implant practices. As a fellow dentist, I humbly urge the drivers of the profession to introspect \& contribute their bit to reinstate the nobility $\&$ respect that was laid upon us through the times of Pierre Fauchard.

\section{Funding}

None.

\section{Acknowledgments}

None.

\section{Conflicts of interest}

The author declares that there is no conflict of interest. 